\title{
The Effect of a Social License From the Community on Acceptance from the Community
}

\author{
Noven Surya Pratama \\ Faculty of Economics and Business \\ University of Lampung \\ Bandar Lampung, Indonesia
}

\author{
Lindrianasari \\ Faculty of Economics and Business \\ University of Lampung \\ Bandar Lampung, Indonesia
}

\author{
Usep Syaipudin \\ Faculty of Economics and Business \\ University of Lampung \\ Bandar Lampung, Indonesia
}

\begin{abstract}
The purpose of this study is to analyze the benefits of assistance to the communities around the mine and the negative influence that communities have received in influencing community trust in influencing their decision to accept the collection of mines that are operated in the middle of their homes. This research was conducted by direct interview with the interviewees. The research sample is 203 residents who live in the mine within a radius of $1 \mathrm{Km}$. The results of this study are the General Benefits of Mining, Infrastructure Benefits from Mining, Impacts on Other Industries, and Environmental Costs do not have a significant effect on Mining Revenues. In contrast, Labor and Community Benefits and Increased Living Costs are associated with the significance of Mining Revenues.
\end{abstract}

Keywords:- Benefit From Mining; Negative Impact From Mining; Acceptance of Mining; Intimacy of Contact.

\section{INTRODUCTION}

The mining industry creates many jobs and promotes the empowerment of mining communities is the essential advantage of the goal for mining acceptance in the community. The mining industry will increase the wealth/acceptance of the general public and improve infrastructure in the area. From the economic side, mining activities contribute very significantly to government revenue and additional tax revenue. Also, mining development can encourage increased investment in social services such as health and education in mining areas (Franks, 2012). Infrastructure development, including roads, port facilities, and railways, and mining operations, can provide direct injections of economic stimulus in the region and help maintain employment in the area around mining (Zhang \& Moffat, 2015). However, in addition to the positive impacts that have been delivered, mining activities also have negative impacts that must be received and considered from each mining activity undertaken. Mining activities carried out by the company cause environmental pollution in residential areas around the mining site. One example of such environmental pollution is that water flowing into residential areas used for daily activities is polluted and hurts public health. The community considers the mining activities carried out by the company does not benefit those in the mining area, and causes more harm to them. Without public acceptance (i.e., social permission to operate), it is challenging for mines to operate effectively or profitably in the long run. So in this study, the aim is to develop an analysis and explain how the community considers the perceived benefits of the presence of mining in the community, and so does the negative impact felt by the community.

\section{LITERATURE REVIEW}

\section{A. Social Exchange Theory}

Social exchange theory assumes that everyone will be rational in evaluating the impacts and benefits caused. Modern social exchange theory has evolved from the work of Homans (1961), Blau (1964), and Emerson (1972). Social exchange is defined as "exchange of activities, tangible or intangible, and beneficial or less beneficial or detrimental; these activities are carried out at least by two parties (Cook, 2015). The social exchange involves obligations that are not explicitly determined; social exchange requires trust between parties (Restubog et al., 2015).

The theory of social exchange is one of the main orientations for the analysis of social interaction and social structure. Social relationships are seen in terms of the advantages of costs and benefits exchanged in interactions. Communities always have their views regarding what compensation they should receive when considering accepting the negative impacts they might feel. Activities undertaken by the company and related to the possibility of environmental changes will affect community acceptance of the company's presence. When implementing a social exchange framework for mining activities, the public will evaluate mining development in terms of benefits and costs gained or experience. As long as the exchange generated gives a more significant benefit from the impact, the action taken is acceptable to the community.

\section{B. Legitimation Theory}

Legitimacy theory (Lindblom, 1994; Suchman, 1995) has a focus on whether an organization's value system is compatible with the system and values of society, and what the organization's goals are to meet the social expectations 
of the community. This theory states that the company will strive to ensure that its operations are within the bounds of applicable norms and accepted by society. The difference between a company's value against the value of society is often defined as a "legitimacy gap," which will affect the company's ability to continue its business activities.

Legitimacy gaps can be reduced by increasing compliance with company operations and community expectations. Social contracts represent the expectations of a dynamic society, where people want to know how companies operate. According to the theory of legitimacy, the existence of social contracts between the company and surrounding communities requires companies to always respond to the environment's existence and pay attention by carrying out operations by environmental values (Guthrie et al., 2004). Companies need to know what expectations are expected by the community when they want to start operational, which may hurt the surrounding community. By knowing the expectations expected by the community, this will increase public acceptance of the company's presence.

\section{Acceptance of Mining}

The community plays an important role and must be considered by mining companies to carry out mining activities smoothly. The results of expectations and the actual reality on the ground will significantly affect community acceptance of mining activities carried out by the company. If the actual reality on the ground from mining activities is worse than expected, community acceptance of mining activities will decrease, and vice versa (Moffat and Zhang, 2014). Acceptance of Mining means acceptance from the community of the company's presence in the community. Acceptance from the community also means that the community supports the activities carried out by the company and considers the activities of the company essential to do because it is beneficial for the community itself. According to the theory of social exchange, the community will weigh the benefits of mining compared to the negative impacts felt in their lives.

Acceptance from the community is essential because it certainly does not want a lot of interference or obstacles when carrying out its operational activities. To that end, obtaining a social license from the community is something that must also be a concern and concern of the company, because by getting the hearts of the community, this means profits for the company both in terms of business and social aspects.

\section{General Benefit From Mining}

One of the actions that can influence and increase the possibility of acceptance from the community is by providing direct benefits to the surrounding community. General Benefits from Mining are benefits that can be obtained by the community in the form of financial compensation, such as cash directly to the community (Zhang \& Moffat, 2015). These benefits can undoubtedly be used directly by the community to meet the basic needs of the community. They can be considered as compensation expected from the community's negative impacts as a result of mining operational activities. Social permission from the community to operate refers to the continued acceptance and approval of mining development by members of the local community and other stakeholders who can influence profitability (Prno \& Scott Slocombe, 2012). In general, companies are encouraged to operate in specific locations because they disturb the environment or socially. Instead, they have to adjust their practices and work in consultation with communities around the mine.

General Benefit from Mining is also related to the provision of compensation to the community as a result of the community being harmed due to the operational activities of the mining company, such as damage to residents' homes resulting from the process of mining activities (Zhang \& Moffat, 2015). General Benefit from Mining provided by the company is expected to be able to make the community more prosperous in terms of economy, because basically, the community wants to change for the better, especially in terms of the economy. Benchmarks for community welfare will be seen from the comparison between before the mining company was present in the middle of the community and afterward. By making the community more prosperous, of course, this will facilitate and assist companies in increasing public trust and lead to acceptance of the company's presence in the community (Zhang \& Moffat, 2015).

\section{E. Infrastructure Benefit From Mining \\ Infrastructure Benefits From Mining relates to the} company's benefits in the form of infrastructure development in locations around the mining area and community dwellings. For example, building bridges and repairing roads in the area around the communities' dwellings. Sometimes mining companies also invest in infrastructure around the communities affected by mining consider it as part of agreements and provisions of local and state governments that are part of the corporate social responsibility agenda or CSR (Harvey \& Bice, 2014). Infrastructure Benefits From Mining that can be offered by companies can also be in the form of social infrastructure development such as the construction of sports fields, places of worship, and public health services (Zhang \& Moffat, 2015). Providing benefits in development should be done by the company adjusted to the surrounding community's needs to avoid futile development. Before carrying out development, the company should hold discussions with the community who live around the community to find out the community's wishes so that the provision of benefits becomes more directed.

\section{F. Employment and Community Benefit from Mining}

Another benefit of the surrounding community is the existence of Employment and Community Benefits from Mining. Mining also encourages improvement in social conditions by creating direct employment (Fleming \& Measham, 2014). Provision of these benefits can be in the form of providing local training programs to the community, such as labor-intensive programs and 
development of a local community that can be directly felt by the community and, in other words, directly related to community empowerment (Zhang \& Moffat, 2015). Employment and Community Benefits from Mining obtained by the community can also be in the form of employment.

Communities can be part of the mining company itself as day laborers and permanent workers and, as a result, will get income that can affect their economy better (Zhang \& Moffat, 2015). Mining management companies are also expected to provide benefits in the form of support and participation in the development of local communities, involved in events held by the community. When the company conducts these activities consistently, the public trust will increase, and eventually, the company can thoroughly receive the company's presence.

\section{G. Increased Living Cost}

The presence of mining companies in the middle of residential areas certainly does not rule out the possibility of hurting the community. The influx of mining workers in the middle of community settlements can put massive pressure on housing stock and prices, raise housing prices around the location and rent financing, and can also increase the cost of living in the cities around the mining site (Fleming \& Measham, 2014). Increased Living Cost can also mean that the community around the mine feels a significant increase in the cost of living when the mining company starts its mining activities around the location of their residence. The increase in costs certainly adds to the economic burden on society and makes this a loss and impact that must be received by the community (Zhang \& Moffat, 2015).

\section{H. Impact on Other Industries}

Mining activities also hurt other industries such as manufacturing, agriculture, and tourism, as well as the environment around the area where people live. Both the construction and production phases of mining development make high demands for skilled and unskilled labor resources. With the existence of mining activities, the location of residences of residents who might potentially be a place of tourism could be lost because of these activities. Besides the tourism sector, other impacts can also be felt by other industries such as the manufacturing and construction sectors. The demand for workers by mining companies has provided significant economic benefits to people's lives; this has resulted in companies from these industries having to offer their workers a higher wage than those offered by the mining industry to be able to get a limited workforce that is life around the mining area, or the company operates (Zhang \& Moffat, 2015).

\section{Environmental Cost}

The impact is most felt by the community mining activities disrupt the environment where people live. For example, mining operations tend to produce dust and noise and impact the quality and quantity of groundwater (Franks, 2012). Risks perceived in the future related to mining activities also include disruption of the natural environment and industry's contribution to future climate change.

\section{HYPOTHESIS AND EQUATION}

A. General Benefit from Mining and Acceptance of Mining

One of the actions that can generate acceptance from the community is by providing benefits from mining for the surrounding community. The benefits from mining obtained by the community in the form of employment, business opportunities (Moffat \& Zhang, 2014), and economic conditions (Zhang \& Moffat, 2015). Benefit from mining in the form of increasing individual and family wealth positively influences community acceptance (Zhang \& Moffat, 2015).

Ha1: General Benefit from Mining has a positive and significant impact on Acceptance of Mining

\section{B. Infrastructure Benefit from Mining and Acceptance of Mining \\ Benefits in the form of improving the state of infrastructure such as road construction, ports, public facilities, and information and telecommunications facilities by mining companies can make people more receptive to mining activities, and infrastructure improvements are essential factors in receiving mining activities (Zhang \& Moffat, 2015).}

Ha2: Infrastructure Benefit from Mining has a positive and significant impact on Acceptance of Mining

\section{Employment and Community Benefit from Mining and Acceptance of Mining \\ Mining activities that can create opportunities and} employment have a positive effect and an essential factor in the acceptance of mining activities (Zhang \& Moffat, 2015). With the opening of mining land in an area will also provide employment opportunities for people in the area. Mining activities in Indonesia have significantly opened up employment opportunities in developing remote areas. The development of new growth centers in several regions has provided benefits in the development of necessary infrastructure, increased state revenue, and employment.

Ha3: Employment and Community Benefits from Mining have a positive and significant impact on Acceptance of Mining. 


\section{Increased Living Cost and Acceptance of Mining}

The increase in the cost of living harms the receipt of mining activities, but the impact is not significant for the community (Zhang \& Moffat, 2015). Mining activities have negative impacts, such as high living costs for the communities around the mine. The high increase in the cost of living can cause the people who live around the mine to be required to spend more money in the fulfillment of daily life. When the community feels disadvantaged, of course, this will make the company have a negative image in the eyes of the community, and this will undoubtedly make public acceptance of the company to decline. The declining trust from the community will make it difficult for companies to obtain social licenses to support the company's smooth operations in conducting mining activities.

Ha4: Increased Living Cost has a negative and significant impact on Acceptance of Mining

\section{E. Impact on Other Industries and Acceptance of Mining}

The study results by Zhang \& Moffat (2015) mention that the higher the negative impact of mining activities on other industries such as tourism, the public perception of mining revenue will be reduced. Other negative impacts are not paying attention to environmental sustainability, logging, excessive waste of activities, ex-mining areas that are left open, and land disputes with surrounding communities. These factors have a negative influence on the Acceptance of Mining. Other negative impacts such as the occurrence of urbanization, the nature of consumerism, agricultural land are decreasing, people's way of life is changing, and there is a shift in livelihoods.

Ha5: Impact on Other Industries has a negative and significant impact on Acceptance of Mining.

\section{F. Environmental Cost and Acceptance of Mining}

The community's perception of the negative impact of mining activities on the environment influences the decline in community income (Zhang \& Moffat, 2015), finding that environmental impacts are essential in receiving or not mining activities. Behavior and community attention to the environment is the most crucial factor in receiving mining activities (Litmanen et al., 2016). The findings of Litmanen et al. (2016), shows that community behavior that is more concerned or concerned about environmental conditions is negatively related to mining activities

Ha6: Environment Cost has a negative and significant impact on the Acceptance of Mining.

\section{EQUATION AND RESEARCH MODEL}

\section{A. Equation}

Acceptance of Mining $=\alpha+\beta_{1} G B M+\beta_{2} I B M+$ $\beta_{3} E C B M+\beta_{4} I L C+\beta_{5} I O O+\beta_{6} E C+\mathrm{e}$

\section{B. Research Model}

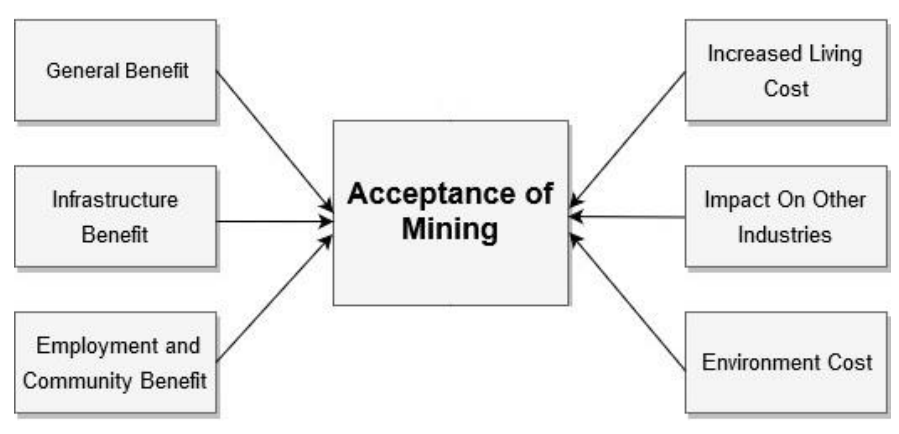

Fig 1

\section{RESEARCH METHOD}

\section{A. Types and Sources of Data}

This type of research is a field survey. Survey research method or simply called survey method is research whose primary source of data and information is obtained from respondents as research samples using questionnaires or questionnaires as data collection instruments. The data source of this research came from speakers who conducted direct interviews to ensure that the data's validity directly came from the people living around the mining area.

\section{B. Research Population and Sample}

This research population is the people who live around the mine within $\pm 1 \mathrm{~km}$ radius of the mine. The sample of this study was 203 respondents living in the area around the mine. Research Variables and Measurements

\section{Independent Variable}

The dependent variable of this study is the Acceptance of Mining. Measurement of this variable refers to research conducted by Zhang \& Moffat 2015, entitled "A balancing act: The role of benefits, impacts, and confidence in governance in predicting acceptance of mining in Australia." The dependent variable in this study was measured using questionnaires number 1 to 5 in the appendix. Questionnaires are given to respondents in the form of statements using the Likert scale 1-7, where the scale of 1 (strongly disagree) to 7 (strongly agree).

\section{$>$ Independent Variable \\ - General Benefit from Mining}

General Financial Benefit is used to determine the welfare of the community around the mine in financial terms since the presence of the mine around the location of their residence. Measurement of this variable is done by conducting interviews using questionnaires number 6 to 9 in the attached questions. In measuring this variable, it will refer to research conducted by Kieren Moffat \& Airon Zhang (2015) with the title "A balancing act: The role of benefits, impacts, and confidence in governance in predicting acceptance of mining in Australia." Questionnaires are given to respondents in the form of statements using a 1-7 Likert scale, where the scale of 1 (strongly disagree) to 7 (strongly agree). 


\section{- Infrastructure Benefit From Mining}

Improvement in infrastructure is used to measure the community's benefits in terms of infrastructure development around the mining area where they live. Measurement of Improvement in Infrastructure refers to research conducted by Kieren Moffat \& Airong Zhang with the title "A balancing act: The role of benefits, impacts, and confidence in governance in predicting mining acceptance in Australia" in 2015. This variable was measured using a number questionnaire 10 to 13 in the attachment to the question. Questionnaires are given to respondents in the form of statements using the Likert scale 1-7, where the scale of 1 (strongly disagree) to 7 (strongly agree).

\section{- Employment and Community Benefit From Mining}

Employment and Community Development is used to determine the company's contribution to the development of communities and communities around the mining area. Measurement of Employment and Community Development refers to research conducted by Kieren Moffat \& Airong Zhang with the title "A balancing act: The role of benefits, impacts, and confidence in governance in predicting acceptance of mining in Australia" in 2015. Measurement of this variable uses a questionnaire number 14 to 17 in the attachment to the question. Questionnaires are given to respondents in the form of statements using the Likert scale 1-7, where the scale of 1 (strongly disagree) to 7 (strongly agree).

\section{- Increased Living Cost}

Increased Living Cost is used to measure the increase in living costs felt by the community around the mine as a result of mining operational activities carried out by the company. Measurement of Increased Living Cost refers to research conducted by Kieren Moffat \& Airong Zhang with the title "A balancing act: The role of benefits, impacts and confidence in governance in predicting acceptance of mining in Australia" in 2015. Measurements made to measure variables. This uses questionnaires number 18 to 20 in the attached questions. Questionnaires are given to respondents in the form of statements using the Likert scale 1-7, where the scale of 1 (strongly disagree) to 7 (strongly agree).

\section{- Impact on Other Industries}

Impact on Other Industry is used to measure the perceived impact on other industries as a result of the company's mining operational activities. Measurement of Impact on Other Industry refers to research conducted by Kieren Moffat \& Airong Zhang with the title "A balancing act: The role of benefits, impacts, and confidence in governance in predicting acceptance of mining in Australia" in 2015. Measurements made to measure This variable uses questionnaires number 21 and 22 in the attached questions. The questionnaire is given to respondents in the form of statements using the Likert scale $1-7$, where the scale of 1 (strongly disagree) to 7 (strongly agree).

\section{- Environmental Cost}

The environmental cost is used to measure the impact caused to the environment around the mining area as a result of mining operational activities carried out by the company. Measurement of Employment and Community Development refers to research conducted by Kieren Moffat \& Airong Zhang with the title "A balancing act: The role of benefits, impacts, and confidence in governance in predicting acceptance of mining in Australia" in 2015. Measurements made to measure This variable uses questionnaires number 23 to 26 in the attached questions. Questionnaires are given to respondents in the form of statements using the Likert scale 1-7, where the scale of 1 (strongly disagree) to 7 (strongly agree).

\section{RESULT AND DISCUSSION}

\section{A. Descriptive Analysis}

The profile of respondents participating in this study is shown in the following table:

\begin{tabular}{|c|c|c|}
\hline Sex & Frequent & Percentage \\
\hline Man & 113 & $55,67 \%$ \\
\hline Woman & 90 & $44,33 \%$ \\
\hline Total & $\mathbf{2 0 3}$ & $\mathbf{1 0 0 \%}$ \\
\hline
\end{tabular}

Tabel 1:- Details of Participants by Gender

From the table, we can see a description of the sex and age of the respondent. When viewed from the gender of male respondents more than women, namely 113 men (55.67\%), women as many as 90 people (44.33\%). The average age of respondents is in the age range 26-45 years as many as 86 people $(42.36 \%)$ and the age range $46-65$ years as many as 90 people $(44.33 \%)$. The average citizen who lives around the mine has completed high school education and has lived near the mining area for more than five years.

\begin{tabular}{|c|c|c|}
\hline Dependent Variable & $\boldsymbol{R}$ Square & $\begin{array}{c}\boldsymbol{R} \text { Square } \\
\text { Adjusted }\end{array}$ \\
\hline Acceptance of Mining & 0,946 & 0,945 \\
\hline
\end{tabular}

Tabel 2:- R-Square Table

R-Squares values in table 2 mentioned that $94.6 \%$ of the independent variables in this study could explain the Acceptance of Mining variable. 
B. Data Analysis

Bootstrapping test results in this study from the PLS analysis are as follows:

\begin{tabular}{|c|c|c|c|}
\hline Research Variable & Original Sample & P-Values & Research Result \\
\hline $\begin{array}{c}\text { General Benefit from Mining-> Acceptance of } \\
\text { Mining }\end{array}$ & 0,304 & 0,061 & Rejected \\
\hline $\begin{array}{c}\text { Infrastructure Benefit From Mining -> Acceptance } \\
\text { of Mining }\end{array}$ & $-0,052$ & 0,190 & Accepted \\
\hline $\begin{array}{c}\text { Employment and Community Benefit from Mining } \\
\text {-> Acceptance of Mining }\end{array}$ & 0,455 & 0,000 & Accepted \\
\hline $\begin{array}{c}\text { Increased Living Cost } \text {-> Acceptance of Mining } \\
\text { Impact on Other Industries -> Acceptance of } \\
\text { Mining }\end{array}$ & 0,057 & 0,005 & Rejected \\
\hline Environmental cost -> Acceptance of Mining & $-0,034$ & 0,068 & Rejected \\
\hline
\end{tabular}

Table 3:- Data Processing Results

The effect of the General Benefit of Mining on Acceptance of Mining shows a path coefficient of 0.304 and a p-value of 0.061. A p-value was more significant than 0.05, which means Hypothesis 1 is rejected. Based on these results it can be interpreted that the General Benefit of Mining does not significantly influence the Acceptance of Mining this means it can be concluded that hypothesis 1 of General Benefit of Mining is not able to be the one that affects Acceptance of Mining from the community around the mine to mining activities. If we associate it with the Social Exchange Theory, for the community, the General Benefit of Mining variable is not the main benefit; that is the reason for them to accept the presence of the mine in the community. This research is by research conducted by Zandvliet and Anderson (2009), which has the result of observations where the money itself is not enough to 'buy' community income around the mining area.

The effect of Improvement in Infrastructure on Acceptance of Mining shows a path coefficient of -0.052 and a p-value of 0.19 . The $p$-value is smaller than 0.05 , but it produces a negative effect; this means that Hypothesis 2 is rejected. Based on these results it can be interpreted that Improvement in Infrastructure does not have a significant positive effect on Acceptance of Mining this means it can be concluded that hypothesis 2 Improvement in Infrastructure does not have a positive and significant effect on Acceptance of Mining from communities around the mine to mining activities. If we associate with Social Exchange Theory, for the community in this study, it is also known that Improvement in Infrastructure is also not the main benefit that can make the community consider and become their reason for accepting the mine's presence in the community.

The effect of Employment and Community Development on Acceptance of Mining shows a path coefficient of 0.455 and a p-value of 0,000 . A p-value of fewer than 0.05 means that Hypothesis 3 is accepted. Based on these results, it can be interpreted that Employment and Community Development has a significant positive effect on Acceptance of Mining. This means that it can be concluded that Hypothesis 3 Employment and Community Development has a positive influence on Acceptance of Mining from the community around the mine to mining activities. These results are in line with the Social Exchange Theory, which says that people tend to consider the benefits and impacts of the company rationally and they feel that community empowerment in the form of job vacancies is a benefit and one of the main reasons that can make them accept the presence of mining in the middle of the place they live.

The effect of Increased Living Cost on Acceptance of Mining shows a path coefficient of 0.057 and a p-value of 0.005 . The p-value is smaller than 0.05 , but the hypothesis's effect is positive, which means that Hypothesis 4 is rejected. Based on these results it can be interpreted that Increased Living Cost is rejected and does not have a significant adverse effect on Acceptance of Mining this means it can be concluded that hypothesis 4 Increased Living Cost does not have a negative and significant effect on Acceptance of Mining from the community around the mine to mining activities but produce a positive influence. If we associate it with the Social Exchange Theory, for the community, the presence of a mine in the middle of their settlement provides more benefits or benefits than negative impacts such as Increased Living costs so that they rationally accept the presence of a mine. This is in line with research conducted by Zhang \& Moffat (2015), which has similar observations where people living in the mining area do not feel the increased living cost incurred from the presence of a mine in the middle of their settlement.

The effect of Impact on Other Industries on Acceptance of Mining shows a path coefficient of 0.034 and a p-value of 0.068 . The $p$-value is more significant than 0.05 , but the effect of the hypothesis is positive; this means that Hypothesis 5 is rejected. Based on these results it can be interpreted that Impact on Other Industries is rejected and does not have a significant adverse effect on Acceptance of Mining this means it can be concluded that 
the hypothesis 5 Impact on Other Industries has no harmful and significant effect on Acceptance of Mining from the community around the mine to activities mining but instead produces a positive influence. If we associate it with Social Exchange Theory, for the community, the presence of a mine in the middle of their settlement gives more benefits or benefits compared to negative impacts such as Impact on Other Industries, so that they rationally accept the presence of a mine.

The influence of the Environmental Cost on Acceptance of Mining shows a path coefficient of -0.165 and a p-value of 0.554. A p-value higher than 0.05, this means that Hypothesis 6 is rejected. Based on these results, it can be interpreted that the Environmental Cost is rejected and does not significantly influence the Acceptance of Mining this means it can be concluded that the hypothesis 6 Environmental Cost does not significantly influence the Acceptance of Mining of the community around the mine on mining activities.

\section{CONCLUSION}

Employment and Community Development in the form of employment is one of the benefits or benefits that can increase the trust of the people who live around the mine, which leads to the acceptance of the mine during the community because it is considered beneficial and can improve the economy of the people living around the mine. The community realizes that the environmental costs arising from mining activities can damage the environment, but this does not have a significant effect on the Acceptance of Mining of the people who live around the mine because the community feels a Balance of Benefit Over Cost, especially with the presence of a lot of labor absorption which generates income for them. The General Benefit of Mining and Improvement in Infrastructure does not have a significant effect on the Acceptance of Mining of the people who live around the mine, because not all people expect benefits in the form of cash assistance or infrastructure development. However, instead, they expect benefits in other forms. Impact on Other Industries and Increased Living Cost does not have a significant effect on the Acceptance of Mining of the people living around the mine because the presence of the mine does not affect their lives or work. So we can conclude that the benefits received by the community are proven to be able to increase the Acceptance of Mining from the community living around the mine and also the negative impact felt by the community can reduce the community Acceptance of Mining. However, in this study, the community did not care about the negative impacts that might arise from mining activities because the main benefit that made them accept mining activities carried out by the company was the empowerment of the surrounding community in the form of opening vacancies at the mine involving the surrounding community as workers.

\section{REFERENCES}

[1]. Besley, J. C. (2010). Public engagement and the impact of fairness perceptions on decision favorability and acceptance. Science Communication, 32(2), 256280. https://doi.org/10.1177/1075547009358624

[2]. Conde, M., \& Le Billon, P. (2017). Why do some communities resist mining projects while others do not? Extractive Industries and Society, 4(3), 681-697. https://doi.org/10.1016/j.exis.2017.04.009

[3]. Cook, K. S. (2015). Exchange: Social. In International Encyclopedia of the Social \& Behavioral Sciences: Second Edition (Second Edi, Vol. 8). Elsevier. https://doi.org/10.1016/B978-0-08-097086-8.32056-6

[4]. De Cremer, D., Tyler, T. R., \& den Ouden, N. (2005). Managing cooperation via procedural Fairness: The mediating influence of self-other merging. Journal of Economic Psychology, 26(3 SPEC. ISS.), 393-406. https://doi.org/10.1016/j.joep.2004.12.004

[5]. Franklin, A. L., \& Pagan, J. F. (2006). Organization Culture as an Explanation for Employee Discipline Practices. Review of Public Personnel Administration, 26(1), $52-73$. https://doi.org/10.1177/0734371X05277335

[6]. Hall, N., Lacey, J., Carr-Cornish, S., \& Dowd, A. M. (2015). Social license to operate: Understanding how a concept has been translated into practice in energy industries. Journal of Cleaner Production, 86, 301310. https://doi.org/10.1016/j.jclepro.2014.08.020

[7]. Hewstone, M., Lolliot, S., Swart, H., Myers, E., Voci, A., Ramiah, A. Al, \& Cairns, E. (2014). Intergroup contact and intergroup conflict. Peace and Conflict, 20(1), 39-53. https://doi.org/10.1037/a0035582

[8]. Moffat, K., \& Zhang, A. (2014). The paths to social license to operate: An integrative model explaining community acceptance of mining. Resources Policy, 39(1), $61-70$ https://doi.org/10.1016/j.resourpol.2013.11.003

[9]. Owen, J. R., \& Kemp, D. (2013). Social license and mining: A critical perspective. Resources Policy, 38(1), https://doi.org/10.1016/j.resourpol.2012.06.016

[10]. Pettigrew, T. F., \& Tropp, L. R. (2006). A metaanalytic test of intergroup contact theory. Journal of Personality and Social Psychology, 90(5), 751-783. https://doi.org/10.1037/0022-3514.90.5.751

[11]. Prno, J., \& Scott Slocombe, D. (2012). Exploring the origins of "social license to operate" in the mining sector: Perspectives from governance and sustainability theories. Resources Policy, 37(3), 346357. https://doi.org/10.1016/j.resourpol.2012.04.002

[12]. Rubin, E. V. (2009). The role of procedural justice in public personnel management: Empirical results from the department of defense. Journal of Public Administration Research and Theory, 19(1), 125-143. https://doi.org/10.1093/jopart/mum035 
[13]. Siegrist, M., Connor, M., \& Keller, C. (2012). Trust, Confidence, Procedural Fairness, Outcome Fairness, Moral Conviction, and the Acceptance of GM Field Experiments. Risk Analysis, 32(8), 1394-1403. https://doi.org/10.1111/j.1539-6924.2011.01739.x

[14]. Terwel, B. W., Harinck, F., Ellemers, N., \& Daamen, D. D. L. (2010). Voice in Political Decision-Making: The Effect of Group Voice on Perceived Trustworthiness of Decision Makers and Subsequent Acceptance of Decisions. Journal of Experimental Psychology: Applied, 16(2), 173-186. https://doi.org/10.1037/a0019977

[15]. Tyler, T. R. (2000). Social Justice: Outcome and Procedure. International Journal of Psychology, 35(2), 117-125. https://doi.org/10.1080/002075900399411

[16]. Zhang, A., \& Moffat, K. (2015). A balancing act: The role of benefits, impacts, and confidence in governance in predicting acceptance of mining in Australia. Resources Policy, 44, 25-34. https://doi.org/10.1016/j.resourpol.2015.01.001

[17]. Zhang, A., Moffat, K., Lacey, J., Wang, J., González, R., Uribe, K., Cui, L., \& Dai, Y. (2015). Understanding the social license to operate of mining at the national scale: A comparative study of Australia, China, and Chile. Journal of Cleaner Production, 108, 1063-1072. https://doi.org/10.1016/j.jclepro.2015.07.097 